\title{
Effects of ethyl-3-nitrooxy propionate and 3-nitrooxypropanol on ruminal fermentation, microbial abundance, and methane emissions in sheep
}

\author{
G. Martínez-Fernández, ${ }^{*}$ L. Abecia, ${ }^{*}$ A. Arco, ${ }^{*}$ G. Cantalapiedra-Hijar, ${ }^{* 1}$ A. I. Martín-García, ${ }^{*}$ E. Molina-Alcaide, ${ }^{*}$ \\ M. Kindermann,† S. Duval, $\ddagger$ and D. R. Yáñez-Ruiz ${ }^{2}$ \\ *Estación Experimental del Zaidín (Consejo Superior de Investigaciones Científicas), Camino del Jueves s/n, 18100 Armilla, Granada, Spain \\ †DSM Nutritional Products, PO Box 2676, Bldg. 241/858, CH-4002 Basel, Switzerland \\ fDSM Nutritional Products, Research Centre for Animal Nutrition and Health, BP 170, F-68305 Saint-Louis Cedex, France
}

\section{ABSTRACT}

The aim of this work was to investigate the effect of feeding ethyl-3-nitrooxy propionate (E3NP) and 3-nitrooxypropanol (3NP), 2 recently developed compounds with potential antimethanogenic activity, in vitro and in vivo in nonlactating sheep on ruminal methane production, fermentation pattern, the abundance of major microbial groups, and feed degradability. Three experiments were conducted, 1 in vitro and 2 in vivo. The in vitro batch culture trial (experiment 1) tested 2 doses of E3NP and 3NP (40 and $80 \mu \mathrm{L} / \mathrm{L}$ ), which showed a substantial reduction of methane production (up to $95 \%$ ) without affecting concentration of volatile fatty acids (VFA). The 2 in vivo trials were conducted over $16 \mathrm{~d}$ (experiment 2) and $30 \mathrm{~d}$ (experiment 3) to study their effects in sheep. In experiment 2, 6 adult nonpregnant sheep, with permanent rumen cannula and fed alfalfa hay and oats (60:40), were treated with E3NP at 2 doses (50 and $500 \mathrm{mg} /$ animal per day). After 7, 14, and $15 \mathrm{~d}$ of treatment, methane emissions were recorded in respiration chambers and rumen fluid samples were collected for VFA analysis and quantification of bacterial, protozoal, and archaeal numbers by real-time PCR. Methane production decreased by $29 \%$ compared with the control with the higher dose of E3NP on d 14 to 15 . A decrease in the acetate:propionate ratio was observed without detrimental effects on dry matter intake. In experiment 3, 9 adult nonpregnant sheep, with permanent rumen cannula and fed with alfalfa hay and oats (60:40), were treated with E3NP or $3 \mathrm{NP}$ at one dose (100 mg/animal per day) over $30 \mathrm{~d}$. On d 14 and d 29 to 30 , methane emissions were recorded in respiration chambers. Rumen fluid samples were collected on d 29 and 30 for VFA analysis and quantification of

\footnotetext{
Received August 21, 2013.

Accepted February 22, 2014

${ }^{1}$ Current address: Institut National de la Recherche Agronomique, UMR 1213, Unité Mixte de Recherches sur les Herbivores, Theix, 63122 St Genès Champanelle, France.

${ }^{2}$ Corresponding author: david.yanez@eez.csic.es
}

bacterial, protozoal, and archaeal numbers by real-time PCR. In addition, on d 22 and 23, samples of oats and alfalfa hay were incubated in the rumen of sheep to determine dry matter ruminal degradation over 24 and $48 \mathrm{~h}$, respectively; no effect was observed $(78.6,78.3$, and $78.8 \%$ of alfalfa and $74.2,74.0$, and $70.6 \%$ of oats in control, E3NP, and 3NP groups, respectively). A reduction in methane production was observed for both additives at d 14 and d 29 to 30 . In both treatments, the acetate:propionate ratio was significantly decreased. Likewise, total concentrations of the analyzed microbial groups in the rumen showed no difference among treatments and doses for both experiments. Both tested compounds showed promise as methane inhibitors in the rumen, with no detrimental effects on fermentation or intake, which would need to be confirmed in lactating animals.

Key words: ethyl-3-nitrooxy propionate, 3-nitrooxypropanol, rumen, methane, sheep

\section{INTRODUCTION}

The inhibition of methane $\left(\mathrm{CH}_{4}\right)$ production by ruminants has long been an objective of ruminant nutritionists. Methane is produced within the rumen by methanogenic archaea. It is a byproduct of ruminal fermentation and constitutes a pathway for the disposal of metabolic hydrogen produced by microbial metabolism. The production of $\mathrm{CH}_{4}$ represents an energy loss of between 2 and $12 \%$ of dietary gross energy (Johnson and Johnson, 1995) and contributes significantly to total anthropogenic greenhouse gas emissions (Hristov et al., 2013). It is obvious that if the energy lost as methane were to be conserved as fermentation products, improved energy retention would lead to increased productivity, in addition to decreasing production of this important greenhouse gas (Moss et al., 2000). Various approaches aimed at reducing methane emissions from enteric fermentation have been studied in many countries (McAllister and Newbold, 2008). The development of new feed additives (mainly based on 
plant extracts) to decrease methane production within the rumen has attracted research efforts over the last 20 yr. The results remain variable and contradictory (Benchaar and Greathead, 2011), thus restricting the uptake and use of these new compounds in the animal feeding market. The reasons behind such restriction may be related to several factors, including the lack of persistency of the effects when they are tested in vivo due to the adaptation of the microbial ecosystem, the variability in concentration of active compounds in plant extracts, the stability of the active compound within the rumen, and side effects that compromise overall ruminal fermentation (Hart et al., 2008).

The development of synthetic compounds with activity specific to metabolic pathways essential to ruminal archaea has shown promising results in recent studies. This may overcome the restrictions associated with the use of plant-derived compounds (Liu et al., 2011; Soliva et al., 2011). Methyl-Coenzyme M (CoM) reductase catalyzes the last step of reduction of $\mathrm{CO}_{2}$ to $\mathrm{CH}_{4}$ by hydrogenotrophic methanogenic archaea (Attwood and McSweeney, 2008). Preliminary observations using an in silico screening approach (Halgren et al., 2004) identified some nitrooxy carboxylic acids with potential to dock into the active site of methyl-CoM reductase.

Therefore, the present study was designed to investigate the effects of 2 compounds - ethyl-3-nitrooxy propionate (E3NP) and 3-nitrooxypropanol (3NP) - on antimethanogenic activity in vitro and in vivo, ruminal fermentation, and microbial abundances.

\section{MATERIALS AND METHODS}

One in vitro and 2 in vivo experiments were conducted. In experiment 1 , the antimethanogenic activity of E3NP and 3NP was assessed in batch cultures over $24 \mathrm{~h}$. In experiment 2, the effects of 2 doses of E3NP on ruminal fermentation, methane production, and microbial abundance were studied in sheep over $16 \mathrm{~d}$, and in experiment 3, single doses of E3NP or $3 \mathrm{NP}$ were tested in sheep over $30 \mathrm{~d}$.

\section{Animals, Diet, and Compound}

Fifteen adult, dry Segureña sheep $(44.3 \pm 4.7 \mathrm{~kg}$ of $\mathrm{BW}$ ) fitted with permanent rumen cannulas were used in experiments 1,2 , and 3 . Throughout the trials, they had free access to water and were fed, twice a day (0900 and $1600 \mathrm{~h}$ ), a diet that consisted of alfalfa hay chopped at 15 to $20 \mathrm{~cm}$ and grain oats in a proportion of 60:40 at approximately 1.1 times the energy requirements for maintenance (Aguilera et al., 1986) and a mineralvitamin supplement (Table 1). The same diet was used as the substrate for the in vitro experiment. Animals
Table 1. Chemical composition of alfalfa hay and oats $(\mathrm{g} / \mathrm{kg}$ of DM unless otherwise noted)

\begin{tabular}{lcc}
\hline Item & Alfalfa hay & Oats \\
\hline $\mathrm{DM}, \mathrm{g} / \mathrm{kg}$ of fresh matter & 907 & 912 \\
$\mathrm{OM}$ & 875 & 975 \\
$\mathrm{CP}^{1}$ & 193 & 103 \\
$\mathrm{NDF}$ & 517 & 263 \\
$\mathrm{ADF}$ & 334 & 67.4 \\
$\mathrm{ADL}$ & 103 & 13.2 \\
Ether extract & 9.4 & 19.9 \\
Gross energy, $\mathrm{MJ} / \mathrm{kg}$ of $\mathrm{DM}$ & 18.5 & 21.1 \\
\hline
\end{tabular}

${ }^{1} \mathrm{CP}=\mathrm{N} \times 6.25$.

were cared for by trained personnel in accordance with the Spanish guidelines for experimental animal protection (Royal Decree No. 1201/2005; Boletin del Estado, 2005) and the European Convention for the Protection of Vertebrates used for Experimental and Other Scientific Purposes (European Commission, 2007). The experimental procedures involved in this study were approved by the Animal Welfare Committee at the Institute of Animal Nutrition (Consejo Superior de Investigaciones Científicas, Madrid, Spain). The temperature, humidity, and air turnover in chambers were carefully monitored with respect to animal welfare conditions. The $\mathrm{CO}_{2}$ concentration was also continuously monitored to ensure good air quality and air flow in the chambers. Animals did not show any stress-related behavior while housed in chambers.

The compounds to be tested were E3NP (99.7\% purity) and 3NP (99.5\% purity), both classified as nitrooxy alkanoic derivates (Figure 1). Both compounds were provided by DSM Nutritional Products (Saint-Louis Cedex, France; Duval and Kindermann, 2012). In experiment 1 , the compounds were directly pipetted into the bottles before inoculation. In experiments 2 and 3, the compounds were provided twice a day through the ruminal cannulas at the time the animals were fed. The corresponding amount of each additive was pipetted onto $10 \mathrm{~g}$ of ground oats and wrapped in cellulose paper immediately before being placed in the rumen via the cannula.

\section{Experimental Design and Sampling}

Experiment 1. Three 24-h incubation runs were carried out with 2 bottles per treatment (including blanks). Treatments were as follows: control (no additive treatment), E3NP at 40 and $80 \mu \mathrm{L} / \mathrm{L}, 3 \mathrm{NP}$ at 40 and $80 \mu \mathrm{L} / \mathrm{L}$, and bromochloromethane $(\mathbf{B C M})$ at 160 and $320 \mu \mathrm{L} / \mathrm{L}$, as a positive antimethanogenic control (Goel et al., 2009). The corresponding molar doses were 124 and $247 \mu M(\mathrm{BCM}), 33$ and $66 \mu M(3 \mathrm{NP})$, and 25 and $50 \mu M$ (E3NP). The substrate incubated was the 

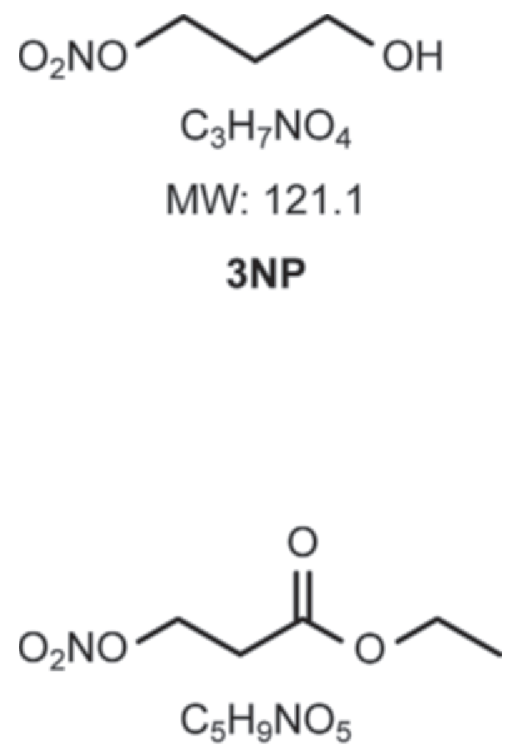

MW: 163.1

\section{E3NP}

Figure 1. Chemical structure of 3-nitrooxypropanol (3NP) and ethyl-3-nitrooxy propionate (E3NP). MW = molecular weight $(\mathrm{g} / \mathrm{mol})$.

same diet provided to animals and was ground to $1 \mathrm{~mm}$ before being weighed into the bottles. The experimental procedure was based on Theodorou et al. (1994). The substrate (500 mg, DM basis) was weighed into 120 -mL serum bottles. Ruminal contents were obtained immediately before the morning feeding from 2 different sheep in each run (6 in total), pooled, and strained through 4 layers of cheesecloth into an Erlenmeyer flask with an $\mathrm{O}_{2}$-free headspace. Filtered rumen fluid was mixed with the buffer solution of Menke and Steingass (1988) in a ratio of $1: 3$ (vol:vol) at $39^{\circ} \mathrm{C}$ under continuous flushing with $\mathrm{CO}_{2}$, and $60 \mathrm{~mL}$ was inoculated in each bottle. Time required from rumen content collection to inoculation of bottles was less than $30 \mathrm{~min}$. Additives were directly pipetted into the bottles before inoculation with buffered rumen fluid. Bottles were sealed with rubber stoppers and aluminum caps, incubated at $39^{\circ} \mathrm{C}$, and withdrawn $24 \mathrm{~h}$ after inoculation. The volume of gas was measured with a glass calibrated syringe (Ruthe, Normax, Marinha Grande, Portugal). Gas samples $(10 \mathrm{~mL})$ were collected at 4, 8, 12, and $24 \mathrm{~h}$ and stored in Hemoguard evacuated glass tubes $(13 \times 100$ mm, ref. no. 366450, Terumo Europe N.V., Leuven, Belgium) before analysis for methane. Bottles were then uncapped, the $\mathrm{pH}$ was measured immediately with a $\mathrm{pH}$ meter, and the fermentation was stopped by swirling the bottles in ice. One milliliter of content was added to $1 \mathrm{~mL}$ of deproteinizing solution [i.e., meta- phosphoric acid $(20 \mathrm{~g} / \mathrm{L})$ and crotonic acid $(4 \mathrm{~g} / \mathrm{L})]$ for VFA determination.

Experiment 2. Six sheep were used. The design consisted of 3 experimental periods of $29 \mathrm{~d}$ each, in which pairs of animals were assigned to each of the 3 treatments: control, E3NP at $50 \mathrm{mg} / \mathrm{d}$, and E3NP at $500 \mathrm{mg} / \mathrm{d}$. Each period included $14 \mathrm{~d}$ of adaptation and then $\mathrm{CH}_{4}$ emissions were measured on $\mathrm{d} 7$ and on d 14 to 15 . Treated animals were progressively adapted to E3NP dose by administering 25, 50, 75, and $100 \%$ of the total dose, respectively, over the first $4 \mathrm{~d}$ of the adaptation period. On d 14 and 15, samples of ruminal contents were collected $2 \mathrm{~h}$ after the morning feeding, subsampled, and immediately frozen before DNA extraction and determination of VFA and $\mathrm{N}_{-} \mathrm{NH}_{3}$ concentration. Body weight was measured on $\mathrm{d} 7$ and 16 , and DMI was recorded daily while sheep were in the chambers (d 7, 14, and 15). A period of 2 wk was allowed as washout between experimental periods.

Experiment 3. Nine sheep were used. The experimental design consisted of a $3 \times 3$ Latin square with 3 sheep per treatment: control, E3NP at $100 \mathrm{mg} / \mathrm{d}$, and $3 \mathrm{NP}$ at $100 \mathrm{~g} / \mathrm{d}$ in each period. Experimental animals were allocated to 3 subgroups of 3 animals each and, within subgroups, were randomly assigned to 1 of the 3 treatments. Each period included 28 d of adaptation to the treatment followed by 2 consecutive days of methane measurements in chambers and collection of rumen samples (d 29 and 30). The dosage was progressively increased over the first $4 \mathrm{~d}$ of the adaptation period as described for experiment 2. Over the course of the adaptation phase, methane was measured on $\mathrm{d}$ 14. In addition, at d 22 and 23, samples of alfalfa hay and oats placed in nylon bags were incubated in the rumen of sheep to determine DM ruminal degradation over 48 and 24 h, respectively. During the $2 \mathrm{~d}$ of methane measurements in chambers (d 29 and 30), rumen content samples were collected $2 \mathrm{~h}$ after the morning feeding, subsampled, and immediately frozen before DNA extraction and determination of VFA and $\mathrm{N}^{-\mathrm{NH}_{3}}$ concentration. Body weight was measured on d 14 and 30 and DMI was registered daily while sheep were in the chambers (d 14, 29, and 30).

\section{Methane Measurement}

Three chambers $(1.8 \mathrm{~m}$ wide $\times 1.8 \mathrm{~m}$ deep $\times 1.5$ $\mathrm{m}$ tall) were used in experiments 2 and 3 . Chamber air temperature was maintained between 15 and $20^{\circ} \mathrm{C}$. Within each chamber, the animals were individually restrained in the same cages as during adaptation. Interruptions occurred daily at 0900 and $1400 \mathrm{~h}$, when the chamber floor was cleaned and the animals were fed. These interruptions had little effect on the daily meth- 
ane emissions because fluxes were calculated 3 times per day and then averaged to derive the 23-h emission value. Airflow and methane concentration were measured for the inflow and outflow ducts of each chamber. Air velocity was continuously monitored throughout the day in the exhaust duct for each chamber. The air stream in each of the 4 ducts (chambers 1, 2, and 3 and background) was subsampled, and methane concentration was measured continuously using a gas analyzer (ADM MGA3000, Spurling Works, Hoddesdon, UK). It took 11 min to sample the airflow sequentially in all inflow and exhausts ducts in the chambers $(3 \mathrm{~min}$ in chambers 1,2 , and 3 , and 2 min for background). In summary, the flux of methane for each chamber was calculated for each measuring day from the difference of fresh-air inflow and chamber exhaust methane concentrations and mean air velocities.

\section{Chemical Analyses}

Volatile fatty acids were analyzed by GC (Isac et al., 1994) and ammonia N concentration by colorimetry following the protocol described by Weatherburn (1967). Feed samples were ground through a $1-\mathrm{mm}$ sieve (14680, Glen Greston Ltd., Stanmore, UK) before analysis; $\mathrm{DM}$, ash, ether extract, and $\mathrm{N}$ contents were determined following AOAC International (2005) official methods 934.01, 942.05, 920.39, and 984.13, respectively. Gross energy was determined in an adiabatic bomb calorimeter (Gallenkamp \& Co. Ltd., London, UK) according to the methodology described by Prieto et al. (1990). Analyses of NDF, ADF, and ADL were performed by the sequential procedure of Van Soest et al. (1991) using the Ankom 2000 Fiber Analyzer (Ankom Technology Corp., Macedon, NY); NDF was assayed with sodium sulfite and without $\alpha$-amylase. Both NDF and ADF were expressed without residual ash. The $\mathrm{N}$ values were determined by the Kjeldahl procedure and converted to CP by multiplying by 6.25 .

The aliquots of the gas produced in experiment 1 were taken in a $10-\mathrm{mL}$ vacuum tube (Venoject, Terumo Europe N.V., Leuven, Belgium) for $\mathrm{CH}_{4}$ concentration analysis. The obtained $\mathrm{CH}_{4}$ concentrations were multiplied by the corresponding gas volumes produced at each sampling time and then added to a 24 -h single production value. The $\mathrm{CH}_{4}$ concentration was determined by GC using an HP Hewlett 5890, Packard Series II gas chromatograph (Waldbronn, Germany) and a HPInnovax column $(25 \mathrm{~m} \times 0.2 \mathrm{~mm} \times 0.2 \mu \mathrm{m}$, Supelco, Madrid, Spain). The carrier gas was $\mathrm{N}$ at a flow rate of $1 \mathrm{~mL} / \mathrm{min}$. Injector and detector temperatures were $250^{\circ} \mathrm{C}$ and $275^{\circ} \mathrm{C}$, respectively. The splitting ratio to the flame-ionization detector was 1:80, and the oven temperature was set at $190^{\circ} \mathrm{C}$ for the entire run.
A sample of $0.5 \mathrm{~mL}$ of gas was injected using a 1-mL Sample-Lock syringe (Hamilton, Nevada, UT). The volume of gas produced $(\mathrm{mL})$ was corrected for standard conditions (105 Pa, $298 \mathrm{~K})$, and the amount of methane produced ( $\mu \mathrm{mol})$ was calculated by multiplying the gas produced $(\mu \mathrm{mol})$ by the concentration of methane in the analyzed sample.

Ruminal degradability was measured on $3 \mathrm{~g}$ of $2-\mathrm{mm}-$ ground feed placed in $5-\times 10-\mathrm{cm}$ nylon bags with a pore size of $50 \mu \mathrm{m}$ (\#R510 Ankom in situ bags, Macedon, NY; Gargallo et al., 2006). The 2 ingredients used in the animals' diets were tested: oats and alfalfa hay. Bags with oats were incubated in the rumen for $24 \mathrm{~h}$, whereas those with alfalfa hay were incubated for 48 $\mathrm{h}$. The incubation times were chosen based on average residing times in the rumen of different feedstuffs. Bags ( 2 bags per feed and period) were placed in the rumen immediately before the morning feeding. At 24 or 48 $\mathrm{h}$, bags were removed from the rumen and frozen at $-20^{\circ} \mathrm{C}$. At the end of every period, the frozen bags were washed in a washing machine using a short (15 min) cold-water program. After washing, the bags were placed in the oven at $60^{\circ} \mathrm{C}$ for $48 \mathrm{~h}$. Ruminal degradability (\%) was calculated as the loss of DM over the incubation time.

\section{Real-Time PCR Analysis}

Samples of rumen contents were freeze-dried and the dry material thoroughly mixed by physical disruption using a bead beater (Mini-bead Beater; BioSpec Products, Bartlesville, OK). Tubes were placed in liquid nitrogen prior and after beating to avoid DNA losses due to overheating. Extraction of DNA was performed from $50 \mathrm{mg}$ of homogenized material using the QIAamp DNA Stool Mini Kit (Qiagen Ltd., West Sussex, UK) following the manufacturer's instructions with the modification that a higher temperature $\left(95^{\circ} \mathrm{C}\right)$ was used for lysis incubation. The DNA samples were used as templates for quantitative real-time PCR amplification. The numbers of total bacteria (Maeda et al., 2003), protozoa (Sylvester et al., 2004), and methanogenic archaea (Denman et al., 2007) were quantified by quantitative real-time PCR as described by Abecia et al. (2012).

\section{Statistical Analyses}

In experiment 1, 3 incubation runs with a 2-replicate batch (per treatment and dose) in each run were carried out, and the statistical model included the fixed effects of dose, with run as a random effect. Data from experiment 1 were analyzed as a univariate model using the GLM procedure of SPSS version 
19.0 (2010; SPSS Inc., Chicago, IL). Data in experiment 2 and 3 were analyzed as a repeated-measures analysis using the GLM procedure of SPSS (version 19.0), with the animal as the experimental unit. In experiment 2 , dose, time (as days of treatment), and dose $\times$ time interaction were considered as fixed effects for the analysis of $\mathrm{CH}_{4}$ production and DMI. The effect of dose was analyzed for VFA, ammonia, total bacteria, total protozoa, and methanogenic archaea. In experiment $3, \mathrm{CH}_{4}$ measurements and DMI were analyzed considering the effects of additive, time (as days of treatment), and additive $\times$ time interaction. The effect of additive was analyzed for VFA, ammonia, DM degradation, total bacteria, total protozoa, and methanogenic archaea. Effects were considered significant at $P \leq 0.05$. When significant differences were detected, differences among means were tested using least significant difference.

\section{RESULTS}

\section{Experiment 1}

The effects of supplementing batch cultures with E3NP, 3NP, and BCM are shown in Table 2. None of the treatments applied affected the concentration of total VFA; however, all treatments and doses significantly decreased the acetate:propionate ratio $(P=0.002)$ and $\mathrm{CH}_{4}$ production $(P=0.001)$. The inhibition of methanogenesis by E3NP (90-95\%) and 3NP (86-95\%) were of the same extent as that of BCM (96\%), and no further reduction was observed when the dose was doubled.

\section{Experiment 2}

Overall, DMI (Table 3) was modified by the addition of E3NP $(P=0.02)$ compared with control throughout the trial, although E3NP at $50 \mathrm{mg} / \mathrm{d}$ resulted in higher DMI $(P=0.001)$ than E3NP at $500 \mathrm{mg} / \mathrm{d}$ at $\mathrm{d} 14$. Methane emission per unit of DMI was significantly reduced with E3NP (up to 29\%) compared with control $(P=0.03)$.

The study of the rumen fermentation parameters showed a shift in the fermentation pathways (Table 4) toward a more propionic-type profile in the rumen of animals receiving E3NP, especially those treated with the higher dose. This was reflected by a decrease in the acetate:propionate ratio $(P=0.03)$ with treatment. An increase $(P=0.01)$ in butyric and isovaleric acids was observed with the higher dose. However, total VFA concentration decreased $(P=0.02)$ in animals treated with E3NP at $500 \mathrm{mg} / \mathrm{d}$ compared with E3NP at 50 $\mathrm{mg} / \mathrm{d}$, but no significant effect was observed compared

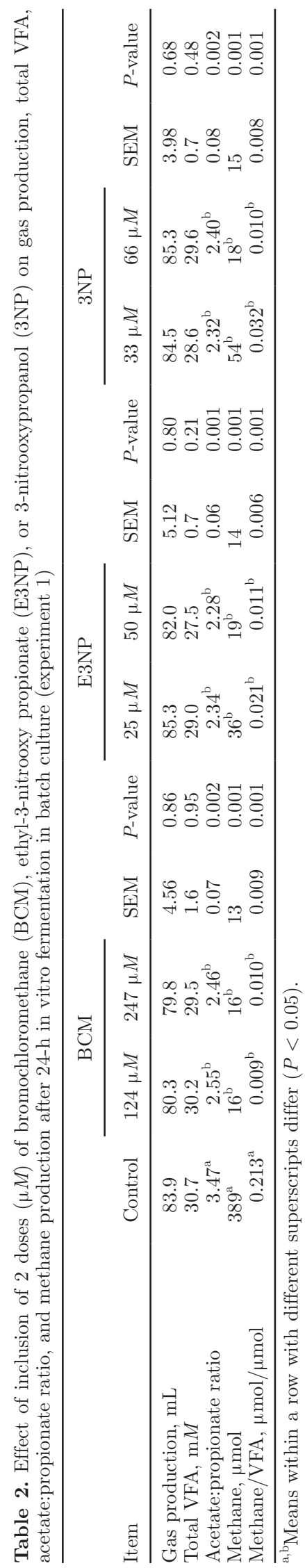


Table 3. Effect of addition of 2 doses of ethyl-3-nitrooxy propionate (E3NP; 50 and $500 \mathrm{mg} / \mathrm{d}$ per animal) on BW, DMI, and methane emissions by sheep on d 7 and from d 14 to 15 (experiment 2)

\begin{tabular}{|c|c|c|c|c|c|c|c|c|c|c|}
\hline Item & \multicolumn{3}{|c|}{ d 7} & \multicolumn{3}{|c|}{ d $14-15$} & SEM & \multicolumn{3}{|c|}{$P$-value } \\
\hline $\mathrm{CH}_{4}, \mathrm{~L} / \mathrm{d}$ & 24.2 & 20.7 & 17.8 & 25.5 & 22.3 & 18.0 & 1.8 & 0.06 & 0.50 & 0.87 \\
\hline $\mathrm{CH}_{4}, \mathrm{~L} / \mathrm{kg}$ of $\mathrm{DMI}$ & 29.1 & 23.4 & 23.3 & $31.8^{\mathrm{a}}$ & $26.3^{\mathrm{a}}$ & $22.7^{\mathrm{b}}$ & 3.2 & 0.03 & 0.40 & 0.54 \\
\hline
\end{tabular}

${ }_{\mathrm{a}, \mathrm{b}}$ Means within a row with different superscripts differ $(P<0.05)$.

with control. Concentration of ammonia was similar among treatments $(P=0.90)$.

Concentrations of the main microbial groups in the rumen did not differ $(P \geq 0.41)$ among treatments (Table 4).

\section{Experiment 3}

Dry matter intake (Table 5) was not affected $(P \geq$ $0.17)$ by treatment or time. Methane emissions per kilogram of DMI were significantly $(P \leq 0.02)$ reduced on d 14 when sheep were treated with either compound. The reductions observed compared with control were 14 and $25 \%$ for E3NP and 3NP, respectively. When methane emissions per kilogram of DMI were recorded 2 wk later, on d 29 and 30, the decrease in methane emissions persisted $(P \leq 0.04)$ and was around $21 \%$ with both compounds.

Rumen fermentation parameters (Table 6) analyzed on d 29 and 30 showed no effect on total VFA concentration, a decrease in the molar proportion of acetate, and an increase in that of propionate. Consequently, the acetate:propionate ratio was significantly $(P=$
0.001) decreased in both treatments. The concentration of ammonia was similar among treatments $(P=0.97)$. The ruminal degradation of DM of alfalfa hay and oats assessed in sacco showed no effect of the additive on rumen degradability. The gene copy numbers of the 3 microbial groups quantified in rumen samples was not $(P \geq 0.3)$ affected by any of the compounds used.

\section{DISCUSSION}

Several studies have documented substantial reductions in methane production by chemical agents such as ionophores, sulfate, nitrate, fumarate, and halogenated methane analogs (Wood et al., 2009; van Zijderveld et al., 2010; Soliva et al., 2011; Abecia et al., 2012). However, the practical use of such compounds is limited by their transient effects, costs of production, availability of compounds, or unfavorable toxicological profile (Hristov et al., 2013). We report here on the potential of 2 new molecules to modify rumen fermentation across in vitro and in vivo assessment.

The results obtained in experiment 1 show potent antimethanogenic activity of E3NP and 3NP. The extent

Table 4. Effect of adding 2 doses of ethyl-3-nitrooxy propionate (E3NP; 50 or $500 \mathrm{mg} / \mathrm{d}$ per animal) on total VFA concentration, VFA profile, ammonia concentration, and concentrations (copy gene numbers/g of fresh matter) of total bacteria (16SrRNA), protozoa (18S rRNA), and methanogenic archaea (mcr $\Delta$ gene) in the rumen of sheep after $15 \mathrm{~d}$ of treatment (experiment 2)

\begin{tabular}{|c|c|c|c|c|c|}
\hline \multirow[b]{2}{*}{ Item } & \multicolumn{3}{|c|}{ E3NP treatment } & \multirow[b]{2}{*}{ SEM } & \multirow[b]{2}{*}{$P$-value } \\
\hline & Control & 50 & 500 & & \\
\hline Total VFA, $\mathrm{m} M$ & $111.2^{\mathrm{ab}}$ & $123.3^{\mathrm{a}}$ & $104.1^{\mathrm{b}}$ & 5.5 & 0.02 \\
\hline Acetate & $70.6^{\mathrm{a}}$ & $71.0^{\mathrm{a}}$ & $65.5^{\mathrm{b}}$ & 0.9 & 0.01 \\
\hline Propionate & 15.7 & 16.8 & 18.8 & 0.8 & 0.06 \\
\hline Butyrate & $6.7^{\mathrm{ab}}$ & $5.6^{\mathrm{a}}$ & $8.1^{\mathrm{b}}$ & 0.6 & 0.01 \\
\hline Isobutyrate & 3.7 & 3.5 & 3.4 & 0.2 & 0.70 \\
\hline Valerate & 1.6 & 1.5 & 1.8 & 0.1 & 0.25 \\
\hline Isovalerate & $1.7^{\mathrm{a}}$ & $1.6^{\mathrm{a}}$ & $2.4^{\mathrm{b}}$ & 0.2 & 0.01 \\
\hline Acetate:propionate ratio & $4.59^{\mathrm{a}}$ & $4.26^{\mathrm{ab}}$ & $3.57^{\mathrm{b}}$ & 0.23 & 0.03 \\
\hline $\mathrm{N}-\mathrm{NH}_{3}, \mathrm{mg} / 100 \mathrm{~mL}$ & 42.5 & 40.5 & 40.1 & 5.5 & 0.90 \\
\hline Total bacteria, $\log _{10}$ & 9.03 & 9.08 & 9.18 & 0.10 & 0.49 \\
\hline Total protozoa, $\log _{10}$ & 6.35 & 6.28 & 6.43 & 0.06 & 0.41 \\
\hline Methanogenic archaea, $\log _{10}$ & 8.49 & 8.57 & 8.45 & 0.22 & 0.95 \\
\hline
\end{tabular}

$\overline{\mathrm{a}, \mathrm{b}}$ Means within a row with different superscripts differ $(P<0.05)$. 
Table 5. Effect of the addition of $100 \mathrm{mg} / \mathrm{d}$ per animal of ethyl-3-nitrooxy propionate (E3NP) or 3-nitrooxypropanol (3NP) on BW, DMI, and methane emissions by sheep measured on d 14 and from d 29 to 30 of treatment (experiment 3 )

\begin{tabular}{|c|c|c|c|c|c|c|c|c|c|c|}
\hline \multirow[b]{2}{*}{ Item } & \multicolumn{3}{|c|}{ d 14} & \multicolumn{3}{|c|}{ d $29-30$} & \multirow[b]{2}{*}{ SEM } & \multicolumn{3}{|c|}{$P$-value } \\
\hline & Control & E3NP & $3 \mathrm{NP}$ & Control & E3NP & $3 \mathrm{NP}$ & & Additive (A) & Time $(\mathrm{T})$ & $\mathrm{A} \times \mathrm{T}$ \\
\hline $\mathrm{CH}_{4}, \mathrm{~L} / \mathrm{d}$ & 24.3 & 21.8 & 19.7 & 22.3 & 20.6 & 18.8 & 1.7 & 0.14 & 0.32 & 0.88 \\
\hline $\mathrm{CH}_{4}, \mathrm{~L} / \mathrm{kg}$ of DMI & 30.0 & 25.6 & 22.3 & 27.4 & 21.5 & 20.9 & 1.8 & 0.003 & 0.04 & 0.62 \\
\hline
\end{tabular}

of inhibition of $\mathrm{CH}_{4}$ production by BCM, E3NP, and $3 \mathrm{NP}(86-96 \%)$ was equivalent to that reported by Goel et al. (2009) in batch culture using BCM (89-94\%). In the current work, the molar doses of BCM (124 and 247 $\mu M), 3 \mathrm{NP}(33$ and $66 \mu M)$ and E3NP $(25$ and $50 \mu M)$ were greater than those used by Goel et al. (2009) in batch cultures $(5$ and $10 \mu M)$. However, the lack of effect on total VFA concentration at both tested doses suggests that fermentation was not compromised, although a clear shift in the fermentation profile was observed, as revealed by the decrease in the acetate:propionate ratio. A reduction in the acetate:propionate ratio has been described as a common feature of several antimethanogens. This indicates a concurrent decrease of methane formation and redirection of hydrogen from methane to more propionic metabolic pathways. Similar observations for total VFA were made by Denman et al. (2007), when they fed BCM to steers, resulting in a methane reduction of $33 \%$. The total mean VFA concentration was unaffected by the treatments but the acetate:propionate ratio was significantly lower in the BCM-treated animals.

In experiment 2, E3NP was provided to sheep at 50 and $500 \mathrm{mg} /$ animal per day. These doses correspond to around 10 and $100 \mathrm{mg} / \mathrm{L}$ of rumen content (68 and $681 \mu \mathrm{M}$, respectively), assuming $11 \%$ of rumen content relative to BW (Abecia et al., 2012). The lower dose $(68 \mu M)$ was decided based on the results obtained in vitro, in which a substantial decrease in $\mathrm{CH}_{4}$ was observed at 25 to $50 \mu \mathrm{M}$, and accounting for an increase of around $80 \%$ of the average dose to compensate the rumen outflow, which in our conditions (animals fed restricted intake) was estimated to be around $3 \% / \mathrm{h}$ (Yáñez-Ruiz et al., 2004). The higher dose $(681 \mu M)$ was chosen to test the potential negative effect of a dose 10 times greater than the lower dose. Treatment with E3NP at $500 \mathrm{mg} / \mathrm{d}$ resulted in a significant $(P<$ $0.05)$ reduction of methane production at $\mathrm{d} 14(29 \%)$, although not as high as that obtained in vitro $(95 \%)$. It was however similar to the decrease $(30 \%)$ achieved in our group with dairy goats treated over 2 mo using BCM supplied at $247 \mu \mathrm{M}$ in the rumen (Abecia et al., 2012). Similar differences between in vitro and in vivo studies have been observed using Japanese horseradish oil by Mohammed et al. (2004), who reported substantially greater inhibitions of methane production in vitro (89\%) than in vivo (18.7\%). The discrepancy in the extent of effectiveness with similar doses may be

Table 6. Effect of the addition of $100 \mathrm{mg} / \mathrm{d}$ per animal of ethyl-3-nitrooxy propionate (E3NP) or 3-nitrooxypropanol (3NP) VFA concentration, VFA profile, ammonia concentration, and concentrations (copy gene numbers/g fresh matter) of total bacteria (16SrRNA), protozoa (18S rRNA), and methanogenic archaea (mcr $\Delta$ gene) in the rumen of sheep on d 29 and 30, as well as DM degradation (DMD, \%) of oats (24 h) and alfalfa hay $(48 \mathrm{~h})$ in the rumen of sheep on $\mathrm{d} 22$ and 23 (experiment 3 )

\begin{tabular}{|c|c|c|c|c|c|}
\hline Item & Control & E3NP & $3 \mathrm{NP}$ & SEM & $P$-value \\
\hline Total VFA, $\mathrm{m} M$ & 114.4 & 115.1 & 114.2 & 9.2 & 0.99 \\
\hline \multicolumn{6}{|l|}{ Individual, $\mathrm{mol} / 100 \mathrm{~mol}$} \\
\hline Acetate & $69.2^{\mathrm{a}}$ & $67.5^{\mathrm{b}}$ & $64.5^{\mathrm{c}}$ & 0.6 & 0.00 \\
\hline Propionate & $14.3^{\mathrm{a}}$ & $16.6^{\mathrm{b}}$ & $17.5^{\mathrm{b}}$ & 0.7 & 0.03 \\
\hline Butyrate & 11.0 & 10.1 & 12.3 & 0.8 & 0.07 \\
\hline Isobutyrate & 2.1 & 2.0 & 2.1 & 0.2 & 0.83 \\
\hline Valerate & 1.5 & 1.8 & 1.8 & 0.2 & 0.32 \\
\hline Isovalerate & 2.0 & 1.9 & 1.8 & 0.2 & 0.79 \\
\hline Acetate:propionate ratio & $4.9^{\mathrm{a}}$ & $4.1^{\mathrm{b}}$ & $3.9^{\mathrm{b}}$ & 0.2 & 0.001 \\
\hline $\mathrm{N}-\mathrm{NH}_{3}, \mathrm{mg} / 100 \mathrm{~mL}$ & 49.3 & 49.8 & 51.0 & 4.6 & 0.97 \\
\hline Alfalfa hay DMD, $\%$ & 78.6 & 78.3 & 78.8 & 1.3 & 0.96 \\
\hline Oats DMD, \% & 74.2 & 74.0 & 70.6 & 1.9 & 0.40 \\
\hline Total bacteria, $\log _{10}$ & 10.74 & 10.91 & 10.96 & 0.09 & 0.35 \\
\hline Total protozoa, $\log _{10}$ & 5.41 & 5.24 & 5.18 & 0.13 & 0.48 \\
\hline Methanogenic archaea, $\log _{10}$ & 8.54 & 8.45 & 8.34 & 0.07 & 0.30 \\
\hline
\end{tabular}

${ }^{a-c}$ Means within a row with different superscripts differ $(P<0.05)$. 
explained by several factors: (1) the compounds used in this study were provided in 2 pulses through ruminal cannulas, coinciding with feeding times, and not mixed with the ration; (2) the degradation rate of the active compounds, if degradation takes place, may differ in vitro and in vivo; (3) a decrease in microbial density and changes in bacterial community structure occur when rumen content is processed before inoculation in vitro, which could be attributed to the exposure of microorganisms to oxygen and the removal of solids during the filtration process (Soto et al., 2012); and (4) potential washout of the rumen or absorption through the rumen wall of the compounds.

A shift in the VFA profile was observed, in agreement with results from experiment 1 . Inhibition of methanogenesis in the rumen is usually associated with an increase in propionate and is believed to be due to the competition for hydrogen (Hungate, 1967). With more hydrogen being available, reductive processes involving propionate production and reductive acetogenesis become thermodynamically favorable (Morgavi et al., 2010). Methanogenesis in the rumen contributes to the homeostasis of the system as it avoids the accumulation of $\mathrm{H}_{2}$ to levels that might inhibit microbial enzymes involved in electron transfer reactions (Morgavi et al., 2010). However, the high hydrogen pressures measured in vitro are likely to be comparatively lower in vivo, as reported by Mitsumori et al. (2012) in goats treated with BCM. The explanation of this lower pressure in vivo is that the majority of hydrogen $(>80 \%)$, which is normally consumed in methane formation, is expelled by the animal. The decrease in acetate and total VFA concentrations by treatment with E3NP at $500 \mathrm{mg} / \mathrm{d}$ could indicate a decrease in fiber degradation, as some fibrolytic microorganisms are more sensitive to high hydrogen partial pressure (Morgavi et al., 2010). This was addressed in experiment 3 and is discussed below. Wolin et al. (1997) demonstrated that a high concentration of hydrogen was able to influence the metabolism of Ruminococcus flavefaciens and Ruminococcus albus, 2 important fiber-degrading species, and was responsible for inhibiting the re-oxidation of reduced nicotinamide adenine dinucleotide $(\mathrm{NADH})$ in these 2 species. Consequently, hydrogen was redirected toward other products such as succinate and ethanol (Wolin et al., 1997). The adaptive changes in rumen microbial ecology due to substantial inhibition of methanogenesis remain unknown, although the increase in propionate production has been observed in most studies. Also, we observed increased isovalerate production with E3NP at $500 \mathrm{mg} / \mathrm{d}$ but not with the lower dose $(50 \mathrm{mg} / \mathrm{d})$, probably as a consequence of disruption of interspecies hydrogen transfer in concordance with observations by
Goel et al. (2009) and Mitsumori et al. (2012) using BCM.

In experiment 3 , the same compound used in experiment $2(\mathrm{E} 3 \mathrm{NP})$ and a related molecule $(3 \mathrm{NP})$ were tested over a longer period $(30 \mathrm{~d})$ at a single dose (100 $\mathrm{mg} / \mathrm{d}$ ). This dose was chosen to avoid the potential negative effect of $500 \mathrm{mg} / \mathrm{d}$ used in experiment 2 on total VFA concentration and intake but doubling the $50 \mathrm{mg} / \mathrm{d}$ dose to ensure effectiveness. Both compounds decreased methane production per kilogram of DMI, with similar VFA profiles to those obtained in experiment 2 at $50 \mathrm{mg} / \mathrm{d}$. The reduction in methane production observed at d 14 persisted on d 29 and 30, which suggests no rapid adaptation of the microbial ecosystem to revert the antimethanogenic activity. A standard 14-d period is used in most in vivo studies to allow the rumen ecosystem to adapt to the tested treatment. However, recent observations suggest that the methanogenic archaea community in the rumen needs around 1 mo to fully adapt to changes in the rumen environment (Williams et al., 2009). In the current study, both compounds were effective in decreasing methane emissions over a 1-mo treatment period, which was further confirmed by a shift in the fermentation pattern. Indeed, the effectiveness in the persistency of synthetic compounds to decrease methane emissions vary in the literature when in vitro results are further tested in vivo. Van Nevel and Demeyer (1996) observed transient effects in sheep treated with a similar halogenated compound, 2-bromoethanesulfonate. The reversion of the effects could be based on at least 2 mechanisms: selection of species of methanogens with greater resistance to the inhibitor or development of microbial species capable of degrading the molecule (Ungerfeld et al., 2004).

On the other hand, as outlined above, the decreased acetate concentration observed in experiment 2 with the higher dose of E3NP might be due to compromised fiber degradation (Newbold et al., 2005). The inhibition of methanogenesis is expected to increase the partial pressure of $\mathrm{H}_{2}$, potentially leading to an inhibition of $\mathrm{H}_{2}$-producing microorganisms such as ruminococci, protozoa, and fungi. The data in the literature suggest that the mechanisms involved in $\mathrm{H}_{2}$ balance in the complex rumen microbiota are not straightforward (Morgavi et al., 2010). To test potential side effects, ruminal degradability of the 2 ingredients of the diet (alfalfa hay and oats) was assessed in experiment 3 by incubating nylon bags in the rumen of the animals. Although the results showed no such effect on DM degradation, this would need to be confirmed in relation to the fiber components. These results could be explained by a mechanism in which Fibrobacter increase in biomass 
to compensate the decrease in fibrolytic ruminococci and rumen fungi, as shown by Mitsumori et al. (2012) in goats treated with BCM. Mitsumori et al. (2012) also revealed that the rumen ecosystem appeared to adapt to the high $\mathrm{H}_{2}$ levels by shifting fermentation to propionate and increasing the population of hydrogenconsuming Prevotella spp.

The quantification of the 3 main microbial groups in the rumen showed that the reduction of methane emissions was not accompanied by decreased concentration of any microbial group. The concentrations of gene copy numbers of bacteria, protozoa, and methanogenic archaea were equivalent to that reported in adult goats (Abecia et al., 2012). Concerning the archaeal numbers, no effect was observed for either of the treatments. The research available on the effect of methane inhibitors on methanogenic archaea in the rumen is variable and sometimes contradictory (Morgavi et al., 2010). Nevertheless, current consensus is that the species distribution (Zhou et al., 2010) or changes in the metabolic activity of some key species (Kang et al., 2013), rather than total archaeal biomass, is what correlates to changes in methane emissions. Kongmun et al. (2011) reported no changes in archaeal abundance in buffalo treated for $21 \mathrm{~d}$ with coconut oil, although a reduction of methane production was observed. Recent studies have reported that a reduction of $30 \%$ in methane production in dairy goats treated for 2 mo with BCM (Abecia et al., 2012) was not accompanied by an effect on the concentration of the methanogenic archaea but that the distribution of archaeal species assessed by denaturing gradient gel electrophoresis was affected (Abecia et al., 2011). Both compounds tested here are thought to target the final step of $\mathrm{CO}_{2}$ reduction to $\mathrm{CH}_{4}$, and specifically the final reduction of methyl-CoM to methane by methyl CoM reductase. In that sense, Ungerfeld et al. (2004) reported that molecules with similar activity in the rumen such as 2-bromoethanesulfonate, 3-bromopropanesulfonate, lumazine, propynoic acid, and ethyl 2-butynoate differently inhibited some of the known key methanogens in the rumen, namely Methanobrevibacter ruminantium, Methanosarcina mazei, and Methanomicrobium mobile. If this was the case for E3NP and 3NP, it could indicate a substantial shift in the species distribution.

\section{CONCLUSIONS}

Both molecules tested in this study, E3NP and 3NP, showed potential to be used as antimethanogenic additives in ruminant diets. The decrease in methane emissions observed in vivo was lower than that in vitro, but persisted over the entire experimental period (1 mo) and was not associated with a reduction in archaeal biomass. It also did not appear to compromise rumen fermentation or intake. This would need to be confirmed in producing animals. A more sustained supply of the compound to the rumen (i.e., mixed with the diet) and longer-term studies deserve further investigation.

\section{ACKNOWLEDGMENTS}

This research was supported by DSM Nutritional Products AG (Kaiseraugst, Switzerland). We gratefully acknowledge T. García, E. Jiménez, I. Jiménez, M. Romero-Huelva, and N. Sánchez (all from (EEZ, CSIC, Granada, Spain) for their technical assistance and DSM Nutritional Products AG for providing ethyl3-nitrooxy propionate and 3-nitrooxypropanol.

\section{REFERENCES}

Abecia, L., A. Martín-García, G. Martínez, N. Tomkins, C. Newbold, and D. Yáñez-Ruiz. 2011. Manipulation of the rumen microbial ecosystem to reduce methane emissions in ruminants through the intervention at early life stage of pre-ruminants and their mothers. Adv. Anim. Biosci. 2:271.

Abecia, L., P. Toral, A. Martín-García, G. Martínez, N. Tomkins, E. Molina-Alcaide, C. Newbold, and D. R. Yáñez-Ruiz. 2012. Effect of bromochloromethane on methane emission, rumen fermentation pattern, milk yield, and fatty acid profile in lactating dairy goats. J. Dairy Sci. 95:2027-2036.

Aguilera, J. F., E. Molina, C. Prieto, and J. Boza. 1986. Estimación de las necesidades energéticas de mantenimiento en ganado ovino de raza segureña. Arch. Zootec. 35:89-96.

AOAC International. 2005. Official Methods of Analysis. 18th ed. AOAC International, Gaithersburg, MD.

Attwood, G., and C. McSweeney. 2008. Methanogen genomics to discover targets for methane mitigation technologies and options for alternative $\mathrm{H}_{2}$ utilisation in the rumen. Anim. Prod. Sci. 48:28-37.

Benchaar, C., and H. Greathead. 2011. Essential oils and opportunities to mitigate enteric methane emissions from ruminants. Anim. Feed Sci. Technol. 166-167:338-355.

Denman, S. E., N. W. Tomkins, and C. S. McSweeney. 2007. Quantification and diversity analysis of ruminal methanogenic populations in response to the antimethanogenic compound bromochloromethane. FEMS Microbiol. Ecol. 62:313-322.

Duval, S., and M. Kindermann. 2012. Nitrooxy alkanoic acids and derivatives thereof in feed for reducing methane emission in ruminants, and/or to improve ruminant performance. S. Duval and M. Kindermann, assignees. US Pat. No. 20,120,315,339.

European Commission. 2007. Commission recommendations of 18 June 2007 on guidelines for the accommodation and care of animals used for experimental and other scientific purposes. Annex II to European Council Directive 86/609. The Commission of the European Communities Publishing, Brussels, Belgium.

Gargallo, S., S. Calsamiglia, and A. Ferret. 2006. Technical note: A modified three-step in vitro procedure to determine intestinal digestion of proteins. J. Anim. Sci. 84:2163-2167.

Goel, G., H. P. S. Makkar, and K. Becker. 2009. Inhibition of methanogens by bromochloromethane: Effects on microbial communities and rumen fermentation using batch and continuous fermentations. Br. J. Nutr. 101:1484-1492.

Halgren, T. A., R. B. Murphy, R. A. Friesner, H. S. Beard, L. L. Frye, W. T. Pollard, and J. L. Banks. 2004. Glide: A new approach for rapid, accurate docking and scoring. 2. Enrichment factors in database screening. J. Med. Chem. 47:1750-1759.

Hart, K. J., D. R. Yáñez-Ruiz, S. M. Duval, N. R. McEwan, and C. J. Newbold. 2008. Plant extracts to manipulate rumen fermentation. Anim. Feed Sci. Technol. 147:8-35.

Hristov, A. N., J. Oh, J. L. Firkins, J. Dijkstra, E. Kebreab, G. Waghorn, H. P. Makkar, A. T. Adesogan, W. Yang, C. Lee, P. J. 
Gerber, B. Henderson, and J. M. Tricarico. 2013. Mitigation of methane and nitrous oxide emissions from animal operations: I. A review of enteric methane mitigation options. J. Anim. Sci. 91:5045-5069.

Hungate, R. E. 1967. Hydrogen as an intermediate in the rumen fermentation. Arch. Mikrobiol. 59:158-164.

Isac, M. D., M. García, J. Aguilera, and A. E. Molina. 1994. A comparative study of nutrient digestibility, kinetics of digestion and passage and rumen fermentation pattern in goats and sheep offered medium quality forages at the maintenance level of feeding. Arch. Tierernahr. 46:37-50.

Johnson, K. A., and D. E. Johnson. 1995. Methane emissions from cattle. J. Anim. Sci. 73:2483-2492.

Kang, S. H., P. Evans, M. Morrison, and C. McSweeney. 2013. Identification of metabolically active proteobacterial and archaeal communities in the rumen by DNA- and RNA-derived $16 \mathrm{~S}$ rRNA gene. J. Appl. Microbiol. 115:644-653.

Kongmun, P., M. Wanapat, P. Pakdee, C. Navanukraw, and Z. Yu. 2011. Manipulation of rumen fermentation and ecology of swamp buffalo by coconut oil and garlic powder supplementation. Livest. Sci. 135:84-92.

Liu, H., J. Wang, A. Wang, and J. Chen. 2011. Chemical inhibitors of methanogenesis and putative applications. Appl. Microbiol. Biotechnol. 89:1333-1340.

Maeda, H., C. Fujimoto, Y. Haruki, T. Maeda, S. Kokeguchi, M. Petelin, H. Arai, I. Tanimoto, F. Nishimura, and S. Takashiba. 2003. Quantitative real-time PCR using TaqMan and SYBR Green for Actinobacillus actinomycetemcomitans, Porphyromonas gingivalis, Prevotella intermedia, tet $Q$ gene and total bacteria. FEMS Immunol. Med. Microbiol. 39:81-86.

McAllister, T., and C. J. Newbold. 2008. Redirecting rumen fermentation to reduce methanogenesis. Aust. J. Exp. Agric. 48:7-13.

Menke, K. H., and H. Steingass. 1988. Estimation of the energetic feed value obtained from chemical analysis and in vitro gas production using rumen fluid. Anim. Res. Dev. 28:7-55.

Mitsumori, M., T. Shinkai, A. Takenaka, O. Enishi, K. Higuchi, Y. Kobayashi, I. Nonaka, N. Asanuma, S. E. Denman, and C. S. McSweeney. 2012. Responses in digestion, rumen fermentation and microbial populations to inhibition of methane formation by a halogenated methane analogue. Br. J. Nutr. 108:482-491.

Mohammed, N., N. Ajisaka, Z. Lila, K. Hara, K. Mikuni, K. Hara, S. Kanda, and H. Itabashi. 2004. Effect of Japanese horseradish oil on methane production and ruminal fermentation in vitro and in steers. J. Anim. Sci. 82:1839-1846.

Morgavi, D. P., E. Forano, C. Martin, and C. J. Newbold. 2010. Microbial ecosystem and methanogenesis in ruminants. Animal 4:1024-1036.

Moss, A. R., J. P. Jouany, and C. J. Newbold. 2000. Methane production by ruminants: Its contribution to global warming. Ann. Zootech. 49:231-253.

Newbold, C. J., S. López, N. Nelson, J. Ouda, R. Wallace, and A. Moss. 2005. Propionate precursors and other metabolic intermediates as possible alternative electron acceptors to methanogenesis in ruminal fermentation in vitro. Br. J. Nutr. 94:27-35.

Prieto, C., J. Aguilera, L. Lara, and J. Fonollá. 1990. Protein and energy requirements for maintenance of indigenous Granadina goats. Br. J. Nutr. 63:155-163.
Boletin del Estado. 2005. Royal Decree No. 1201/2005 of 10 October on the Protection of Animals used for Experimentation and Other Scientific Purposes. Pages 34367-34391 in Boletin del Estado. Spanish Government Publishing, Madrid, Spain.

Soliva, C. R., S. L. Amelchanka, S. M. Duval, and M. Kreuzer. 2011. Ruminal methane inhibition potential of various pure compounds in comparison with garlic oil as determined with a rumen simulation technique (Rusitec). Br. J. Nutr. 106:114-122.

Soto, E., D. Yáñez-Ruiz, G. Cantalapiedra-Hijar, A. Vivas, and E. Molina-Alcaide. 2012. Changes in ruminal microbiota due to rumen content processing and incubation in single-flow continuousculture fermenters. Anim. Prod. Sci. 52:813-822.

Sylvester, J. T., S. K. Karnati, Z. Yu, M. Morrison, and J. L. Firkins. 2004. Development of an assay to quantify rumen ciliate protozoal biomass in cows using real-time PCR. J. Nutr. 134:3378-3384.

Theodorou, M. K., B. A. Williams, M. S. Dhanoa, A. B. McAllan, and J. France. 1994. A simple gas production method using a pressure transducer to determine the fermentation kinetics of ruminant feeds. Anim. Feed Sci. Technol. 48:185-197.

Ungerfeld, E. M., S. Rust, D. Boone, and Y. Liu. 2004. Effects of several inhibitors on pure cultures of ruminal methanogens. J. Appl. Microbiol. 97:520-526.

Van Nevel, C. J., and D. Demeyer. 1996. Control of rumen methanogenesis. Environ. Monit. Assess. 42:73-97.

Van Soest, P. J., J. B. Robertson, and B. A. Lewis. 1991. Methods for dietary fiber, neutral detergent fiber and nonstarch polysaccharides in relation to animal nutrition. J. Dairy Sci. 74:3583-3597.

van Zijderveld, S. M., W. J. Gerrits, J. A. Apajalahti, J. R. Newbold, J. Dijkstra, R. A. Leng, and H. B. Perdok. 2010. Nitrate and sulfate: Effective alternative hydrogen sinks for mitigation of ruminal methane production in sheep. J. Dairy Sci. 93:5856-5866.

Weatherburn, M. W. 1967. Phenol-hypochlorite reaction for determination of ammonia. Anal. Chem. 39:971-974.

Williams, Y. J., S. Popovski, S. M. Rea, L. C. Skillman, A. F. Toovey, K. S. Northwood, and A. D. G. Wright. 2009. A vaccine against rumen methanogens can alter the composition of archaeal populations. Appl. Environ. Microbiol. 75:1860-1866.

Wolin, M., T. Miller, and C. Stewart. 1997. Microbe-microbe interactions. Pages 467-491 in The Rumen Microbial Ecosystem. P. N. Hobson and C. Stewart, ed. Springer, London, UK.

Wood, T. A., R. J. Wallace, A. Rowe, J. Price, D. R. Yáñez-Ruiz, P. Murray, and C. J. Newbold. 2009. Encapsulated fumaric acid as a feed ingredient to decrease ruminal methane emissions. Anim. Feed Sci. Technol. 152:62-71.

Yáñez-Ruiz, D. R., A. Moumen, A. M. Garcia, and E. M. Alcaide. 2004. Ruminal fermentation and degradation patterns, protozoa population, and urinary purine derivatives excretion in goats and wethers fed diets based on two-stage olive cake: Effect of PEG supply. J. Anim. Sci. 82:2023-2032.

Zhou, M., E. Hernandez-Sanabria, and L. L. Guan. 2010. Characterization of variation in rumen methanogenic communities under different dietary and host feed efficiency conditions, as determined by PCR-denaturing gradient gel electrophoresis analysis. Appl. Environ. Microbiol. 76:3776-3786. 